\title{
Distance-Dependent Increase in AMPA Receptor Number in the Dendrites of Adult Hippocampal CA1 Pyramidal Neurons
}

\author{
Bertalan K. Andrásfalvy and Jeffrey C. Magee \\ Neuroscience Center, Louisiana State University Health Science Center, New Orleans, Louisiana 70112
}

The Schaffer collateral pathway provides hippocampal CA1 pyramidal cells with a fairly homogeneous excitatory synaptic input that is spread out across several hundred micrometers of their apical dendritic arborizations. A progressive increase in synaptic conductance, with distance from the soma, has been reported to reduce the location dependence that should result from this arrangement. The excitatory synaptic contacts within this pathway primarily use AMPA- and NMDA-type glutamate receptors. To investigate the underlying mechanism of the increased distal excitatory postsynaptic conductance, we used outside-out patches and a fast application system to characterize the properties and distribution of synaptic glutamate receptors across the range of apical dendrites receiving Schaffer collateral input. We observed an approximately twofold increase in AMPA-mediated current amplitude $(0.3-0.6 \mathrm{nA})$ in the range of CA1 apical dendrites that receive a uniform density of Schaffer collateral input ( 100-250 $\mu \mathrm{m}$ from soma). NMDAmediated current amplitude, however, remained unchanged. We analyzed the current kinetics, agonist affinity, single-channel conductance, maximum open probability, and reversal potential of AMPA receptors and did not find any differences. Instead, the number of AMPA receptors present in our patches increased approximately twofold. These data suggest that an increase in the number of AMPA receptors present at distal synapses may play an important role in the distance-dependent scaling of Schaffer collateral synapses.

Key words: CA1 neuron; apical dendrite; AMPA receptor; nonstationary fluctuation analysis; single-channel conductance; MK-801; extrasynaptic and synaptic NMDA receptor
The elaborately branching dendrites of hippocampal CA1 pyramidal neurons receive and process information from thousands of synaptic inputs. One of the simplest ways that dendrites shape incoming activity is to reduce the amplitude and increase the width of EPSPs (Rall, 1962; Jack and Redman, 1971; Jaffe and Carnevale, 1999). Because the cable filtering properties of the dendrites are responsible for this transformation, the effect increases with the distance an EPSP propagates. In this case, the impact of synaptic input would depend on the dendritic location of the active synapses, with more distant synapses having a blunted effect when compared with those located in more proximal regions. It has been reported recently, however, that unitary EPSP amplitude at the site of the synapse increases with distance from the soma and that this increase helps counterbalance some of the filtering effects of the dendrites (Stricker et al., 1996; Magee and Cook, 2000). The final result is that, for Schaffer collateral input to CA1 pyramidal cells, unitary EPSP amplitude at the soma does not show a marked dependence on the dendritic location of the activated synapse.

A progressive increase in unitary synaptic conductance appears to be primarily responsible for the increase in dendritic EPSP amplitude observed in CA1 pyramidal neurons (Stricker et al., 1996; Magee and Cook, 2000). Several other studies, in the hippocampus as well as in other CNS regions, have also reported synaptic efficacy to be relatively location independent. These studies further suggest that an increase in synaptic conductance is

\footnotetext{
Received June 6, 2001; revised Aug. 20, 2001; accepted Sept. 17, 2001.

This work was supported by National Institutes of Health Grant NS 35865 and NS 39458 and the Alfred P. Sloan Foundation.

Correspondences should be addressed to Bertalan K. Andrásfalvy, Neuroscience Center, Louisiana State University Health Science Center, 2020 Gravier Street, New Orleans, LA 70112. E-mail: bandra@1suhsc.edu.

Copyright (C) 2001 Society for Neuroscience $0270-6474 / 01 / 219151-09 \$ 15.00 / 0$
}

the primary mechanism (Inasek and Redman, 1973; Korn et al., 1993; Stricker et al., 1996; Alvarez et al., 1997). Finally, the distal apical dendrites of both neocortical and hippocampal pyramidal neurons have been found to be more sensitive to glutamate than the proximal dendrites (Pettit and Augustine, 2000; Frick et al., 2001).

To further investigate potential postsynaptic mechanisms underlying the increased synaptic conductance of distal synapses, we directly recorded from the site of input using outside-out patches made from dendritic regions receiving Schaffer collateral synaptic input. Rapid application of glutamate to excised patches was used to estimate various postsynaptic properties, including AMPA receptor (AMPAR) numbers, affinity, single-channel conductance, maximum open probability, channel kinetics, and current-voltage ( $I-V)$ relationships in hippocampal CA1 pyramidal neurons. Although we found no evidence of any location dependence of AMPA receptor subunit composition or channel modulation, we did observe a greater than twofold increase in AMPA receptor numbers. The data suggest that distal synapses contain a larger number of postsynaptic AMPA receptors compared with proximal synapses and that this elevation in receptor number could participate in generating the distance-dependent increase in unitary synaptic conductance found in these cells.

\section{MATERIALS AND METHODS}

Preparation and visualization of hippocampal slice. Hippocampal slices $(400 \mu \mathrm{m})$ were prepared from 6- to 12-week-old Sprague Dawley rats using previously described standard procedures (Magee, 1998). Experiments were conducted using an upright Ziess (Oberkochen, Germany) Axioscope fit with differential interference contrast optics using infrared illumination. Patch pipettes (5-11 $\mathrm{M} \Omega$ ) were pulled from borosilicate glass (EN-1; Garner Glass, Claremont, CA) and filled with an internal solution containing (in mM): $140 \mathrm{KMeSO}_{4}, 1$ BAPTA, 10 HEPES, 4 $\mathrm{NaCl}, 0.28 \mathrm{CaCl}_{2}, 4.0 \mathrm{Mg}_{2} \mathrm{ATP}, 0.3 \mathrm{Tris}_{2} \mathrm{GTP}$, and 14 phosphocreatine, 
pH 7.3 with $\mathrm{KOH}$. Currents were recorded in voltage-clamp mode using an Axopatch 200B amplifier (Axon Instruments, Foster City, CA), filtered at $2 \mathrm{kHz}$ and digitized at $20 \mathrm{kHz}$ using Igor Pro XOPs (WaveMetrics Inc., Lake Oswego, OR). The normal bath external solution contained $125 \mathrm{~mm} \mathrm{NaCl}, 2.5 \mathrm{KCl}, 1.25 \mathrm{~mm} \mathrm{NaH}_{2} \mathrm{PO}_{4}, 25 \mathrm{~mm} \mathrm{NaHCO}_{3}, 2 \mathrm{~mm}$ $\mathrm{CaCl}_{2}, 1 \mathrm{mM} \mathrm{MgCl}_{2}$, and $25 \mathrm{~mm}$ dextrose, bubbled with $95 \% \mathrm{O}_{2}$ and $5 \%$ $\mathrm{CO}_{2}$ at room temperature, $\mathrm{pH}$ 7.4. All neurons had resting potentials between -60 and $-75 \mathrm{mV}$.

Formation and size estimation of dendritic patches. Outside-out patches were excised from apical dendrites to apical tufts $(0-300 \mu \mathrm{m})$. Pipettes with a resistance of $5-11 \mathrm{M} \Omega$ had an estimated diameter tip of $\sim 1.5-2$ $\mu \mathrm{m}$. Sodium channel density is relatively uniform along the dendrite (Magee and Johnston, 1995; Colbert and Johnston, 1996). Thus, to examine whether the surface area of patches excised at different locations along the dendrite were the same, peak $\mathrm{Na}^{+}$current amplitudes were examined. Outside-out patches were held at $-80 \mathrm{mV}$, and membrane voltage was stepped to $-20 \mathrm{mV}$ for $100 \mathrm{msec}$. Consistent with previous findings, sodium channel densities were independent of patch location (soma, $16.07 \pm 3.03 \mathrm{pA} ; 125 \mu \mathrm{m}, 20.27 \pm 4.85 \mathrm{pA} ; 250 \mu \mathrm{m}, 17.5 \pm 5.05$ $\mathrm{pA}$ ), indicating that patch size was approximately uniform.

Fast application. Fast application of agonist was performed as described previously (Colquhoun et al., 1992). Briefly, double-barreled application pipettes were fabricated from theta glass tubing, and solutions were perfused through control and agonist barrels at a rate of $\sim 0.3$ $\mathrm{ml} / \mathrm{min}$ by means of a multilined peristaltic pump. The puffer external solution contained (in mM): $125 \mathrm{NaCl}, 2.5 \mathrm{KCl}, 1.25 \mathrm{NaH}_{2} \mathrm{PO}_{4}, 10$ HEPES, $2.5 \mathrm{CaCl}_{2}$, and 50 dextrose, $\mathrm{pH}$ 7.4. The $20-80 \%$ exchange times varied between 100 and $200 \mu$ sec. Outside-out patches were placed in front of the control barrel. Movement of the application pipette, by means of a piezoelectric element, was used to apply agonist to the patch membrane. After each patch recording, the application system was tested by breaking the patch and measuring the open tip current caused by a jump from a 10 to a $100 \%$ puffer external solution. In addition, puffer solutions containing different concentrations of agonist and/or antagonist were exchanged using solenoid valves.

Estimation of synaptic versus extrasynaptic portion by electric stimulation. Afferent axons were stimulated by a tungsten bipolar electrode (A-M Systems, Carlsborg, WA), located within $10-25 \mu \mathrm{m}$ of the dendrite. Trains of three to five consecutive pulses at a frequency of $100 \mathrm{~Hz}$ were applied every $20 \mathrm{sec}$ for $10 \mathrm{~min}$ to stimulate glutamate release from adjacent nerve terminals. Synaptic stimulation was large enough to evoke several action potentials during the train. These experiments were performed at $34-35^{\circ} \mathrm{C}$ to decrease glutamate spillover. In addition, the CA3 region of the hippocampus was removed to avoid spontaneous glutamate release, and $10 \mu \mathrm{M}$ bicuculline methiodide was added to the external bath solution. Furthermore, the bath external solution contained $1 \mathrm{mM} \mathrm{Mg}^{2+}$ to reduce spontaneous NMDA channel openings. Application of $20 \mu \mathrm{M}$ $(5 R, 10 S)-(+)-5$-methyl-10,11-dihydro-5H-dibenzo [a,d] cyclohepten-5,10imine/dizocilpine (MK-801) (Research Biochemicals, Natick, MA) to the bath external solution was used to block NMDA receptors that were gated by the stimulated synaptic activity. In addition, the effects of MK-801 were tested without electrical stimulation in the presence of 0.5 $\mu \mathrm{M}$ external TTX (Research Biochemicals). To determine the amount of NMDA channel block, outside-out patches were excised from the stimulated region of the apical dendrite $10 \mathrm{~min}$ after MK-801 washout.

Data acquisition and analysis. Acquiring, analysis, and fitting of data were performed using interactive programs (Igor Pro). AMPA current activation and deactivation were fit by single-exponential function, whereas desensitization was best fit by double-exponential function. The rise times were determined as the time during which the current rises from 20 to $80 \%$ of the peak value. Patches showing rise times $>1 \mathrm{msec}$ were assumed to have an improper patch configuration and were removed from analysis.

The concentration-dependent relationship for AMPA-activated peak current was determined using increasing concentrations of glutamate (10 $\mu \mathrm{M}$ to $10 \mathrm{~mm}$ ) applied by $100 \mathrm{msec}$ application pulse. Concentrationresponse data were fitted by the Hill equation: effect $=$ effect $_{\text {max }} /[1+$ $\left.\left(\mathrm{EC}_{50} / c\right)^{n}\right]$, where $c$ is the agonist concentration, $n$ is the Hill coefficient, and $\mathrm{EC}_{50}$ is the concentration at which the half-maximal response was obtained.

Microscopic properties of AMPA channels were examined using nonstationary fluctuation analysis (Sigworth, 1980). AMPA currents were evoked every $2-3 \mathrm{sec}$ by a $1 \mathrm{msec}$ pulse of $10 \mathrm{~mm}$ glutamate in the presence of $1 \mathrm{~mm} \mathrm{Mg}^{2+}$. Between 20 and 100 traces per patch were obtained for analysis. The mean variance $\left(\sigma^{2}\right)$, determined from all responses, was plotted against the mean current for all responses. The plot was fitted with the following function: $\sigma^{2}=i I-(1 / N) I^{2}+\sigma_{\mathrm{b}}^{2}$, where $I$ is the total current, $i$ is the single-channel current, $N$ is the number of available channels in the patch, and $\sigma_{\mathrm{b}}{ }^{2}$ is the variance of the background noise.

Single-channel conductance $(\gamma)$ was determined as the chord conductance: $\gamma=I\left(V_{\mathrm{h}}-V_{\text {rev }}\right)$, where $V_{\mathrm{h}}$ is the holding potential, and $V_{\text {rev }}$ is assumed to be $0 \mathrm{mV}$.

The open probability $\left(P_{\mathrm{o}}\right)$ is determined by the following equation: $P_{\mathrm{o}}=I /(i / N)$.

Numeric values are given as means \pm SEM. Error bars in the figures indicate SE and are plotted only if they exceed the size of the symbol. Statistical significance was examined using Student's $t$ test at the 5\% level of confidence.

\section{RESULTS}

\section{AMPA current amplitude versus distance}

Outside-out patches were excised (Jonas and Sakmann, 1992; Spruston et al., 1995) from the apical dendrites of CA1 pyramidal neurons at various locations in stratum radiatum, ranging from stratum pyramidale to the border of the perforant path in the stratum lacunosum moleculare (S.L.M.). Dendrites within this region form spiny glutamatergic synapses with the axons of CA3 pyramidal neurons comprising the Schaffer collateral pathway. Patches were voltage clamped at $-80 \mathrm{mV}$, and AMPA currents were activated by $1 \mathrm{msec}$ pulses of $1 \mathrm{~mm}$ glutamate using a rapid glutamate application system (Clements et al., 1992).

The peak amplitude of the AMPA current increased approximately threefold for patches excised from the soma compared with patches excised from distal regions [soma, $192 \pm 52(n=6)$; dendrite $\sim 250 \mu \mathrm{m}, 566 \pm 74 \mathrm{pA}(n=14) ; p<0.005]$. Anatomical studies have shown that there are few spines, and therefore Schaffer collateral synapses, formed on the proximal portion of rodent hippocampal CA1 pyramidal neurons (soma to just $<100$ $\mu \mathrm{m}$ distal) (Andersen et al., 1980; Bannister and Larkman, 1995; Trommald et al., 1995). At this point $(\sim 100 \mu \mathrm{m})$, spine density reaches a constant value in rodent hippocampal slices that is maintained over the entire span of the Schaffer collateral input to the apical dendrites ( $\sim 1.0$ spines $/ \mu \mathrm{m}^{2}$ ) (Andersen et al., 1980; Bannister and Larkman, 1995; Trommald et al., 1995).

Therefore, much of the initial increase in AMPA current from the soma to $100 \mu \mathrm{m}$ distant can be the result of the increase in synapse density (Andersen et al., 1980; Bannister and Larkman, 1995; Trommald et al., 1995). The remaining approximately twofold increase in dendritic AMPA current amplitude, however, occurs across dendritic regions that have a constant spine density [from $276 \pm 42 \mathrm{pA}$ at $100 \mu \mathrm{m}(n=11)$ to $566 \pm 74 \mathrm{pA}$ at $250 \mu \mathrm{m}$ distal $(n=14) ; p<0.005$ ] (Fig. $1 A)$. The slight decrease in AMPA current observed in the most distal patches $(300 \mu \mathrm{m})$ is likely the result of these patches being in or near S.L.M in which spine density has been observed to again decrease $(0.60 \pm 0.17$ spines $\left./ \mu \mathrm{m}^{2}\right)$.

The variability of AMPA current amplitude between patches could be the result of several factors, including patch area, the number of synapses per patch, and the number of receptors per synapse. The smallest AMPA current amplitudes appear to be uniform across the dendritic axis, and this is reminiscent of the previous observation that the smallest-amplitude EPSCs are also independent of distance from the soma. These data suggest that only a subset of all synapses may be scaled with distance.

In summary, we observed an approximately twofold increase in AMPA receptor current across the range of CA1 apical dendrite that receives a uniform density of Schaffer collateral input (Fig. $1 B)$. In general terms, the increase in current amplitude could be 
A

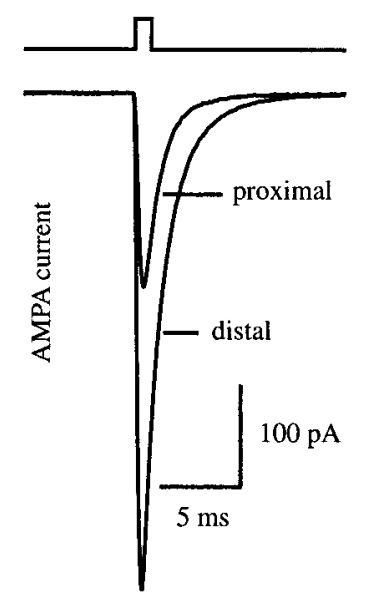

B

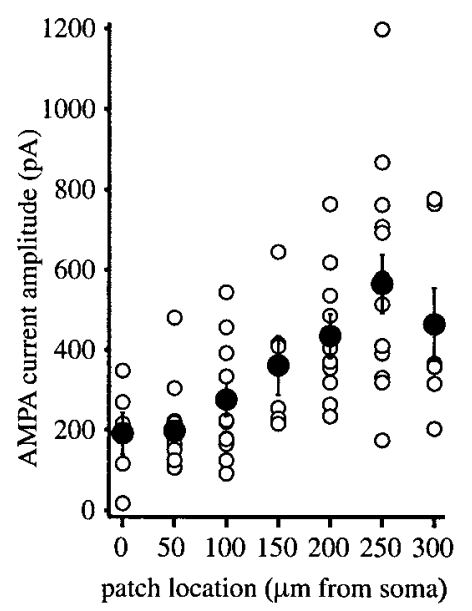

A

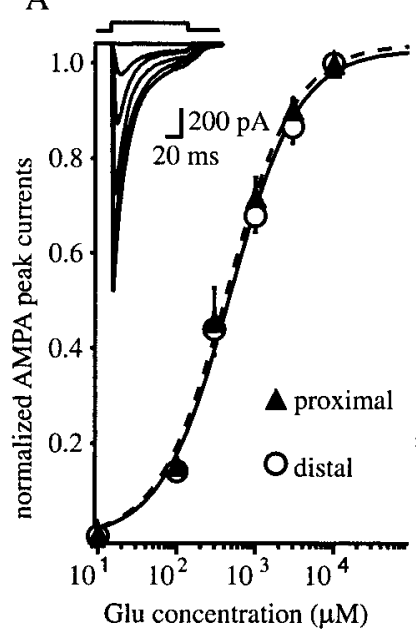

B

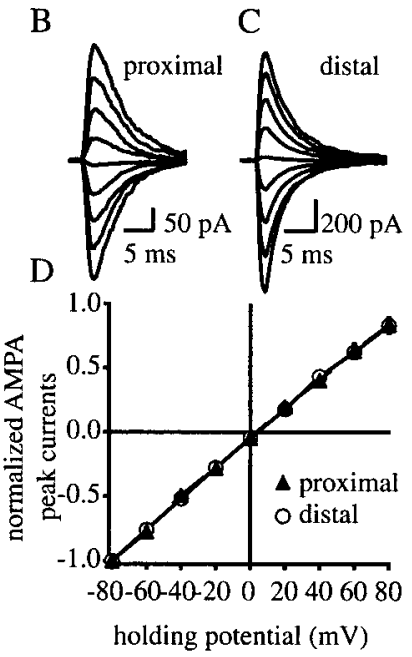

Figure 1. AMPA receptor-mediated glutamate currents in excised patches from different dendritic locations. $A$, Currents activated by $1 \mathrm{msec}$ application of $1 \mathrm{~mm}$ glutamate to outside-out patches excised from either a proximal ( $\sim 50 \mu \mathrm{m}$ from soma) or distal ( $\sim 250 \mu \mathrm{m}$ from soma) dendritic location. Currents were recorded in the presence of $1 \mathrm{mM} \mathrm{Mg}^{2+}$ and in the absence of glycine. Each trace is an average of five sweeps $\left(V_{\mathrm{h}}\right.$ was -80 $\mathrm{mV}) . B$, AMPA receptor-mediated mean current amplitudes are plotted against the location of the excised patches from the soma $(n=69)$. Current amplitude increases approximately threefold across the range. Open circles are the peaks of single patches, and filled circles are the means of these patches with SE bars.

the result of differences in the number of channels present in our patches or to differences in the properties of these channels. The experiments described below were designed to distinguish between these two possibilities.

\section{Agonist affinity}

To determine whether receptor glutamate affinity increased with distance from the soma, we examined dose-response relationships for AMPA-activated current from proximal and distal locations. Increasing concentrations of glutamate $(10 \mu \mathrm{M}$ to $10 \mathrm{mM}$, $100 \mathrm{msec}$ pulse) were applied to patches excised from 50 and 250 $\mu \mathrm{m}$ distal from soma. All peak current values were normalized to the peak responses (10 mM glutamate) and then plotted against concentration (Fig. $2 A$ ). After being fit by a binding isotherm, dose-response curves did not show any significant shifts, with the $\mathrm{EC}_{50}$ of the proximal patches being equal to that of distal patches [436 $\mu \mathrm{M}(n=6)$ and $479 \mu \mathrm{M}(n=7)$, respectively]. These data suggest that the agonist affinity of AMPA receptor is uniform with distance from the soma in CA1 pyramidal neurons.

\section{Current-voltage relationship}

Differences in rectification or reversal potential can suggest possible AMPA receptor subunit composition change (Mosbacher et al., 1994). We determined the $I-V$ relationship of dendritic AMPA channels from outside-out patches excised at various locations along the dendrite. Patches were held at $-80 \mathrm{mV}$, and membrane voltage was stepped up to $+80 \mathrm{mV}$ in $20 \mathrm{mV}$ increments (Fig. 2B,C). Peak currents were measured and normalized to the maximum current recorded at $-80 \mathrm{mV}$. Proximal $(50 \mu \mathrm{m})$ and distal $(250 \mu \mathrm{m})$ AMPA currents displayed a linear $I-V$ relationship and had reversal potentials of $4.2 \pm 1.82 \mathrm{mV}(n=4)$ and $4.4 \pm 1.45 \mathrm{mV}(n=6)$, respectively (Fig. $2 D)$. The slope conductance $\left(G_{\mathrm{m}}\right)$ of the proximally excised patches was $2.56 \pm$ $0.44 \mathrm{nS}$ compared with $7.96 \pm 1.68 \mathrm{nS}$ for distal patches.
Figure 2. Agonist affinity and voltage dependence of AMPA receptormediated glutamate current. $A$, Mean amplitude of AMPAR currents evoked by fast application of $10-10^{4} \mu \mathrm{M}$ glutamate with $100 \mathrm{msec}$ pulses to proximal patches ( $\sim 50 \mu \mathrm{m}$ from soma; $n=6$; dashed line with filled triangles $)$ and distal patches ( $\sim 250 \mu \mathrm{m}$ from soma; $n=7$; solid line with open circles). Currents were normalized to the response at $10 \mathrm{~mm}$ glutamate. $B, C$, AMPA currents evoked by the application of $1 \mathrm{~mm}$ glutamate for $1 \mathrm{msec}$ ( $V_{\mathrm{h}}$ was -80 to $+80 \mathrm{mV}, 20 \mathrm{mV}$ steps) to proximal $(B)$ and distal $(C)$ excised patches. Each trace is a single sweep. $D$, Mean amplitude of AMPA currents for different holding potentials $\left(V_{\mathrm{h}}\right.$ was -80 to $+80 \mathrm{mV}, 20 \mathrm{mV}$ steps) during fast application of $1 \mathrm{~mm}$ glutamate for 1 msec to proximal ( $\sim 50 \mu \mathrm{m}$ from soma; $n=5$; dashed line with filled triangles $)$ and distal $(\sim 250 \mu \mathrm{m}$ from soma; $n=6$; solid line with open circles) patches. Currents were normalized to the response at $-80 \mathrm{mV}$. In most cases, the size of the symbols are bigger than the SE bars. In all experiments, $0.1-1 \mathrm{~mm} \mathrm{Mg}^{2+}$ was added, with no additional glycine.

\section{Kinetics}

Because the kinetic properties of AMPA receptor-mediated current are important for shaping glutamatergic EPSCs, we examined the location dependence of AMPAR kinetics. The kinetic properties of the AMPA currents were studied using glutamate pulses ranging in duration from 1 to $100 \mathrm{msec}$. For all durations, the currents rose rapidly to a peak and decayed within 10-20 msec, producing identical peak currents. The rise time of the current evoked by a $1 \mathrm{msec}$ pulse of $1 \mathrm{~mm}$ glutamate could be fit by a single rising exponential, with a time constant of $0.58 \pm 0.02$ msec and a $20-80 \%$ rise time of $0.47 \pm 0.01 \mathrm{msec}$, across the dendrites $(n=69)$ (Fig. $3 A$ ). The current deactivation could be fit by a single exponential, with a time constant of $2.8 \pm 0.1 \mathrm{msec}$ (Fig. $3 B$ ) with no location-dependent differences observed across the somatodendritic axis. During $100 \mathrm{msec}, 1 \mathrm{~mm}$ glutamate pulses, the current decayed with a double-exponential time course having time constants of $7.6 \pm 0.30 \mathrm{msec}\left(\tau_{1}\right.$, fast component, $90.3 \pm 0.84 \%)($ Fig. $3 C)$ and $25.69 \pm 1.38 \mathrm{msec}\left(\tau_{2}\right.$, slow component, $9.7 \pm 0.84 \%$ ) (Fig. $3 D$ ). There were no location-dependent differences in the desensitization kinetics or in ratio of fast and slow component observed ( $p>0.05$ ) (Fig. $3 E$ ).

\section{Concentration dependence of rise time and desensitization time course}

The rise time and desensitization of glutamate-activated AMPA current decreased in a concentration-dependent manner. The $20-80 \%$ rise time decreased with increasing glutamate concentration ( $1 \mathrm{msec}$ pulses of $100 \mu \mathrm{M}$ to $10 \mathrm{~mm}$ ) from $1.9 \pm 0.1$ to $0.2 \pm$ $0.01 \mathrm{msec}$ on patches excised from $50 \mu \mathrm{m}$ from soma $(n=6)$. The 

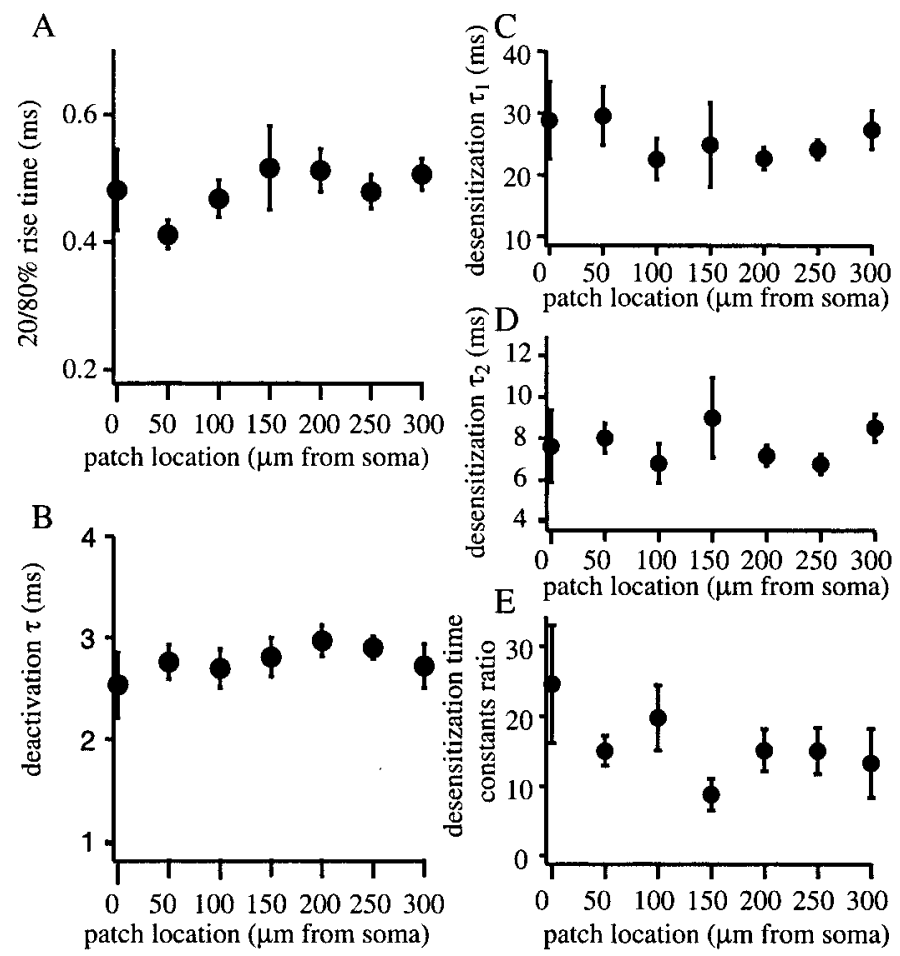

Figure 3. Kinetic properties of AMPAR-mediated glutamate currents versus location. $A$, Mean of $20-80 \%$ rise time of AMPA current evoked by $1 \mathrm{msec}$ application of $1 \mathrm{~mm}$ glutamate on outside-out membrane patches excised from various locations of apical dendrites. $B$, Mean of deactivation time constants $(\tau)$ of the same AMPA currents evoked as in A. $C$, Mean of fast desensitization time constants $\left(\tau_{1}\right)$ of AMPA currents evoked by $100 \mathrm{msec}$ application of $1 \mathrm{~mm}$ glutamate to outside-out patches taken from various locations of apical dendrites. $D$, Mean of slow desensitization time constants $\left(\tau_{2}\right)$ of the same currents as in C.E, Mean of the desensitization time constant ratio of AMPA currents shown in $B$ and $C$. In all experiments, $0.1-1 \mathrm{mM} \mathrm{Mg}^{2+}$ was added with no additional glycine. In each figure, error bars represent the SEM $(n=69)$.

same decrease was seen from $2.1 \pm 0.2 \mathrm{msec}$ with $100 \mu \mathrm{M}$ to $0.2 \pm$ $0.04 \mathrm{msec}$ with $10 \mathrm{~mm}$ glutamate on patches excised from $250 \mu \mathrm{m}$ $(n=6)$ (Fig. 4A). The decay phase of the current (evoked by 100 msec pulses of $100 \mu \mathrm{M}$ to $10 \mathrm{~mm}$ glutamate) traces was fit with the sum of two exponential functions. The predominant fast component $\left(\tau_{1}\right)$ showed a concentration-dependent decrease from $9.7 \pm$ $1.5 \mathrm{msec}$ with $100 \mu \mathrm{M}$ glutamate to $6.6 \pm 0.7 \mathrm{msec}(n=12)$ with $10 \mathrm{~mm}$ glutamate. No difference was found in values between proximally $(n=6)$ or distally $(n=6)$ excised patches. The fast desensitization time constant was plotted against glutamate concentration from both locations together (Fig. 4B).

\section{Nonstationary fluctuation analysis}

We next examined several single-channel properties of dendritic AMPA receptors, namely the single-channel conductance and maximum open probability $\left(P_{\mathrm{o} \text {,max }}\right)$, to determine whether there were any location-dependent differences. The single-channel conductance of AMPA channels $(\gamma)$ was estimated using nonstationary fluctuation analysis of current evoked by $1 \mathrm{msec}$ pulses of 10 mu glutamate (Sigworth, 1980). Between 20 and 100 traces per patches were obtained for analysis. The mean variance $\left(\sigma^{2}\right)$, determined from all responses, was plotted against the mean current for all responses (Fig. 5A,B). The plot was fit by a parabola (see Materials and Methods) to yield estimates of $\gamma$ and the number of available channels $(N)$. Data from $125 \mu \mathrm{m}$ from the
A

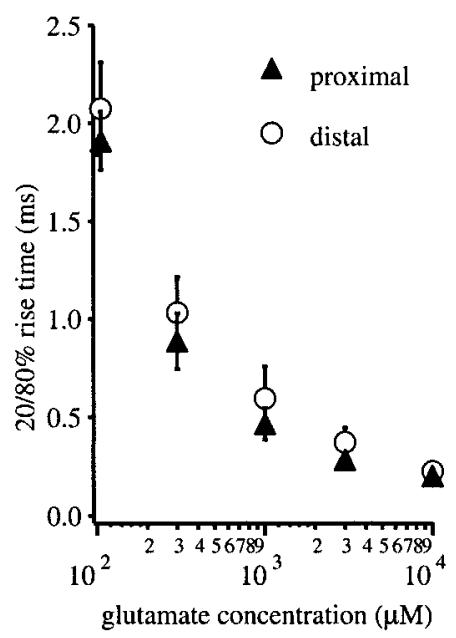

B

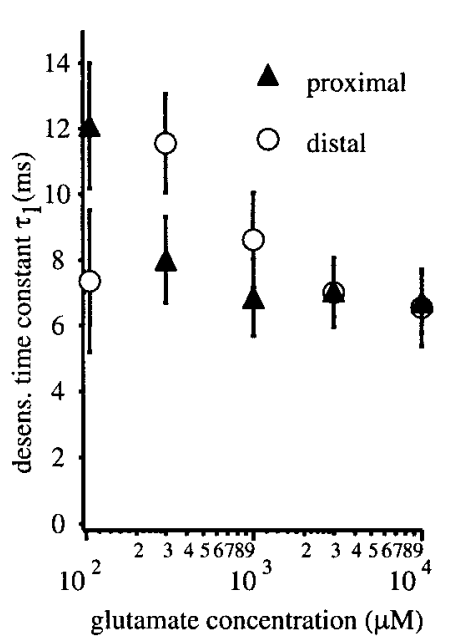

Figure 4. Concentration dependence of AMPA current rise and desensitization. A, Concentration dependence of AMPA current $20-80 \%$ rise time for a $100 \mathrm{msec}$ application of various concentrations of glutamate $\left(100-10^{4} \mu \mathrm{M}\right)$. Data from proximal $(\sim 50 \mu \mathrm{m}$ from soma; $n=6$; dashed line with filled triangles) and distal ( $\sim 250 \mu \mathrm{m}$ from soma; $n=6$; solid line with open circles) patches are shown. Glutamate concentration is shown in $\log$ scale. $B$, Concentration dependence of the fast desensitization time constant $\left(\tau_{1}\right)$ with $100 \mathrm{msec}$ application of glutamate for proximal $(\sim 50$ $\mu \mathrm{m}$ from soma; $n=6$; dashed line with filled triangles $)$ and distal $(\sim 250$ $\mu \mathrm{m}$ from soma; $n=6$; solid line with open circles) patches. Glutamate concentration is shown in log scale.

soma $(n=4)$ and $250 \mu \mathrm{m}$ from soma $(n=5)$ resulted in similar values for $\gamma$ of $9.83 \pm 0.69$ and $9.42 \pm 0.95 \mathrm{pS}$, respectively (Fig. $5 C)$. The probability of any given channel being open at the peak of the response $\left(P_{\mathrm{o}, \max }\right)$ was also similar in both locations: $0.83 \pm$ 0.01 and $0.84 \pm 0.02$, respectively (Fig. 5C). An approximately twofold increase in channel number was detected between the groups $(N=467 \pm 42$, proximal $125 \mu \mathrm{m}$ from soma; $N=1041 \pm$ 206, distal $250 \mu \mathrm{m}$ from soma; $p<0.05$ ) (Fig. 5D). These data, together with that described above, strongly suggest that the observed increase in AMPA current amplitude is the result of an increase in the number of channels present in the patch and not to any alteration in AMPA receptor properties.

\section{NMDA current amplitude versus distance}

NMDA currents were activated on excised patches by $10 \mathrm{msec}$ pulses of $1 \mathrm{~mm}$ glutamate in the presence of $10 \mu \mathrm{M}$ glycine with 5 $\mu \mathrm{M} \quad \mathrm{CNQX}$ or $1 \mu \mathrm{M}$ 2,3-dihydroxy-6-nitro-7-sulfonylbenzo[F]quinoxaline. The peak amplitude of NMDA current does not change significantly with distance from the soma (Fig. $6 A$ ), because NMDA currents from patches excised from the soma and distal dendrites $(250 \mu \mathrm{m})$ had peak current amplitudes of $71.63 \pm 19.35 \mathrm{pA}(n=6)$ and $52.33 \pm 10.19 \mathrm{pA}(n=10 ; p>$ $0.05)$, respectively. Furthermore, dendritic NMDA currents do not change in patches excised at regions between 100 and $250 \mu \mathrm{m}$ distal to the soma $[54.34 \pm 10.97 \mathrm{pA}(n=6) ; 52.33 \pm 10.19 \mathrm{pA}$ $(n=10) ; p>0.05$ ] (Fig. 6B).

\section{Kinetics}

The kinetic properties of the NMDA current were studied using glutamate pulses ranging in duration from 1 to $3 \mathrm{sec}$. For all duration applications, the currents rose slowly to a peak within 
A

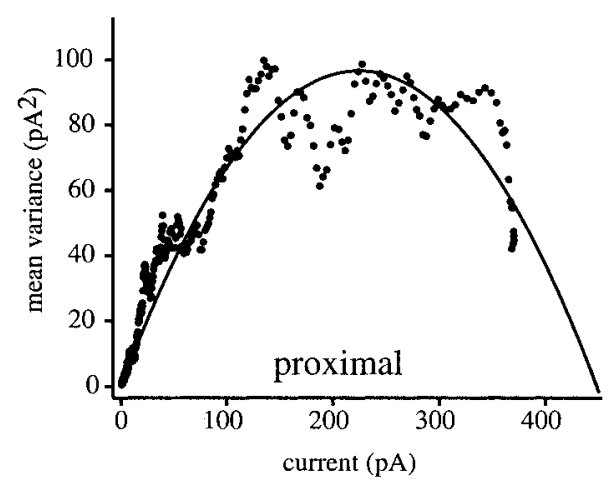

B

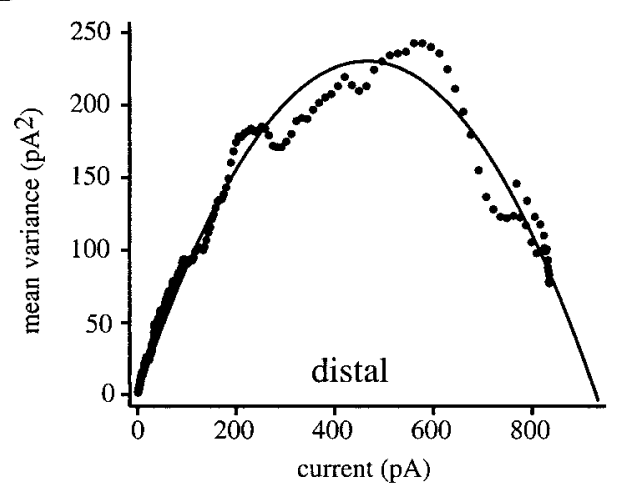

$\mathrm{C}$

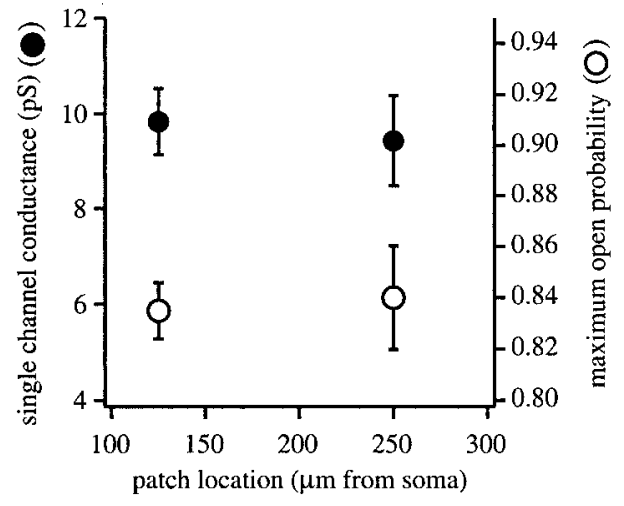

D

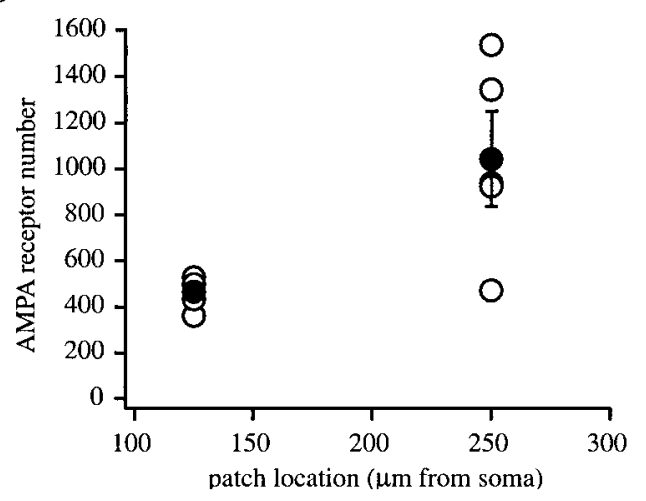

Figure 5. Nonstationary fluctuation analysis of AMPA receptormediated glutamate current. Mean variance plotted as a function of the mean current for a proximal $(A)$ and distal $(B)$ patch. Solid line is fit of the data by a parabolic equation (see Materials and Methods) that was used
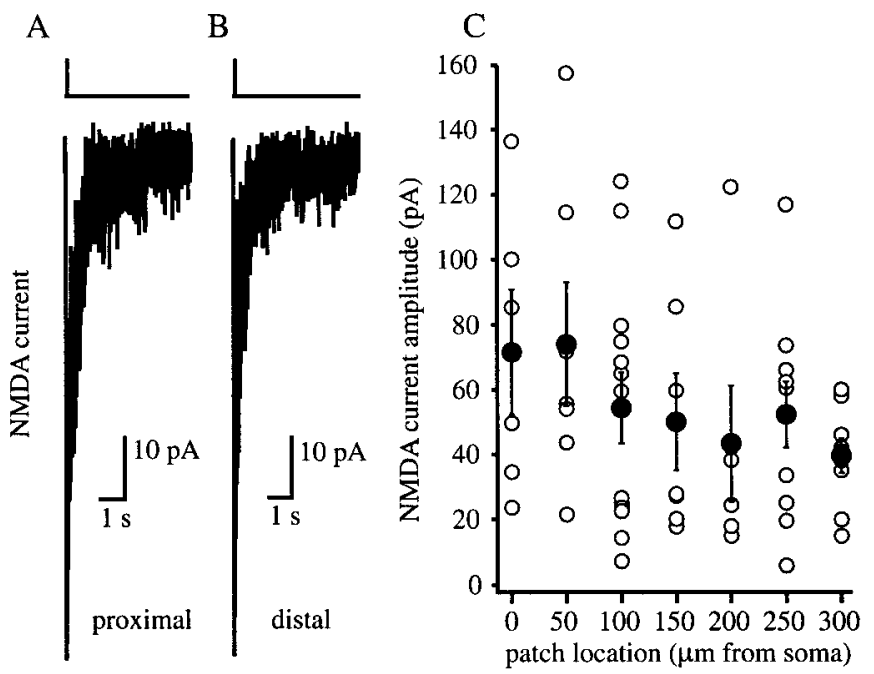

Figure 6. NMDA receptor-mediated glutamate currents in patches excised from different distances from soma. NMDA receptor-mediated currents activated by a $10 \mathrm{msec}$ pulse of $1 \mathrm{~mm}$ glutamate to either proximal $(A)(\sim 50 \mu \mathrm{m}$ from soma $)$ or distal $(B)(\sim 250 \mu \mathrm{m}$ from soma $)$ patches show the same amplitudes. Currents were recorded in the presence of $10 \mu \mathrm{M}$ glycine and in the absence of $\mathrm{Mg}^{2+}$. Each trace is an average of five sweeps $\left(V_{\mathrm{h}}\right.$ was $\left.-80 \mathrm{mV}\right)$. $C$, NMDA receptor-mediated mean current amplitudes are plotted against the location of the excised patches from soma on apical dendrite $(n=60)$. Open circles are the peaks of single patches; filled circles are the means of these patches with SE bars.

5-20 msec, producing identical peak currents. The rise time course of the current evoked by a $1 \mathrm{~mm}, 10 \mathrm{msec}$ glutamate pulse can be described by one rising exponential. The rising time constant was $6.46 \pm 0.7 \mathrm{msec}$ (data not shown), and the $20-80 \%$ rise time was $8.58 \pm 0.78 \mathrm{msec}$ across the dendrites $(n=52)$ (Fig. $7 A)$. The same current decayed with a double-exponential time course, having time constants of $252.5 \pm 21.8 \mathrm{msec}\left(\tau_{1}, 61 \pm\right.$ $1.8 \%$ ) (Fig. $7 B, D)$ and $1.66 \pm 0.15 \mathrm{sec}\left(\tau_{2}, 39 \pm 1.8 \%\right)$ (Fig. $7 C, D)$. There were no location-dependent differences in the activation and deactivation kinetics of NMDA receptor-mediated currents $(p>0.05)$. To determine the time constant of desensitization, 3-sec-long glutamate pulses were used. From 27 patches, 14 did not show any or very small desensitization, and the decay could not be fit by an exponential function. In 13 cases, the single-exponential time constant was $760.26 \pm 66.82 \mathrm{msec}$ (data not shown).

\section{Estimation of the proportion of synaptic receptors}

It is likely that our patches contain a mix of synaptic and extrasynaptic receptors. Therefore, we used the "irreversible" activitydependent NMDA receptor blocker MK-801 to determine the relative amount of synaptic versus extrasynaptic NMDA receptors in our patches (Rosenmund et al., 1995). Before pulling outside-out patches, we used a stimulus protocol that should

to determine single-channel conductance $(\gamma)$, channel number $(N)$, and maximum open probability $\left(P_{\mathrm{o}, \max }\right)$. Proximal patch from $\sim 125 \mu \mathrm{m}$ from soma and distal patch $\sim 250 \mu \mathrm{m}$ from soma. $C$, Single-channel conductance (left axis, filled circles) and maximum open probability (right axis, open circles) versus location of the patches. Currents were evoked by a 1 msec application of $10 \mathrm{~mm}$ glutamate with $1 \mathrm{mM} \mathrm{Mg}^{2+}$ and in the absence of glycine. $D$, AMPA receptor number $(N)$ versus patch location determined from the same patches as in $C$. Open circles are the $N$ of single patches; filled circles are the mean of these patches with SE bars. 


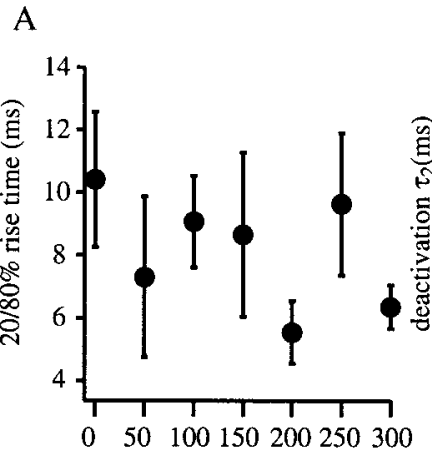

patch location ( $\mu \mathrm{m}$ from soma)

B

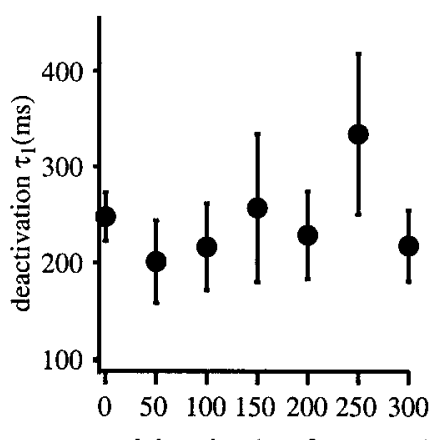

patch location ( $\mu \mathrm{m}$ from soma)
$\mathrm{C}$

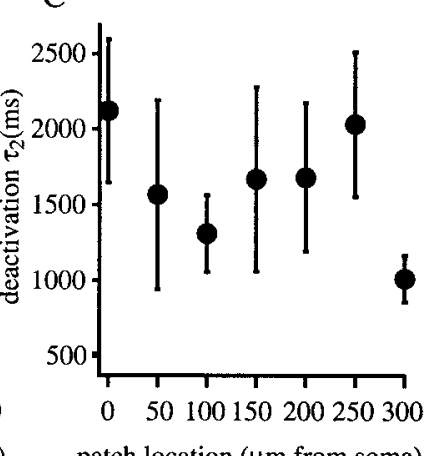

D

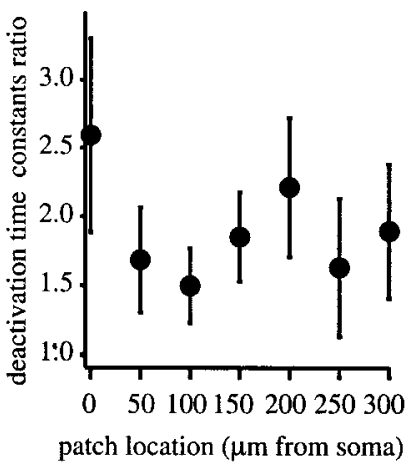

Figure 7. Kinetic properties of NMDAR-mediated glutamate currents versus location. $A$, Mean of NMDA current $20-80 \%$ rise time for currents evoked by $10 \mathrm{msec}$ application of $1 \mathrm{~mm}$ glutamate to outside-out membrane patches excised from various locations of apical dendrites. $B$, Mean of fast deactivation time constants $\left(\tau_{1}\right)$ for NMDA currents evoked as in $A$. $C$, Mean of slow deactivation time constants $\left(\tau_{2}\right)$ of NMDA currents as in $A$ and $B . D$, Mean of deactivation time constant ratio of the NMDA currents evoked as in $B$ and $C$. Currents were recorded in the presence of $10 \mu \mathrm{M}$ glycine and in the absence of $\mathrm{Mg}^{2+}$. Each point is an average of five sweeps $\left(V_{\mathrm{h}}\right.$ was $\left.-80 \mathrm{mV}\right)$.

predominately block synaptic receptors while leaving extrasynaptic receptors relatively unaffected. After localized electrical stimulation (see Materials and Methods), outside-out patches were excised from the synaptically active regions of the dendrites. NMDA currents were then evoked using the fast application system, and the current amplitude was monitored over time to assess the amount of NMDA receptors blocked by MK-801. To speed the recovery from block, patches were depolarized every second minute from -80 to $+20 \mathrm{mV}$, and three to four glutamate pulses were applied for $500 \mathrm{msec}$. The proportion of current recovered from $\mathrm{MK}-801$ block was used as an relative index of the amount of synaptic receptors in the patches. As control, we used patches excised from proximal regions of the apical dendrite in which there are few synapses and therefore mostly extrasynaptic receptors, as well as patches from the distal part of the dendrite that had received no synaptic stimulation (data under these two conditions were pooled in Fig. 8C).

Patches from distal segments of dendrites with evoked synaptic activity showed a greater than ninefold increase in NMDA current over the 10 min recording period (Fig. $8 C$ ) (in two cases, current increased over 20 -fold after $20 \mathrm{~min}$ ). Control patches showed only an approximately twofold increase for the same time course. Any significant movement of NMDA receptors between
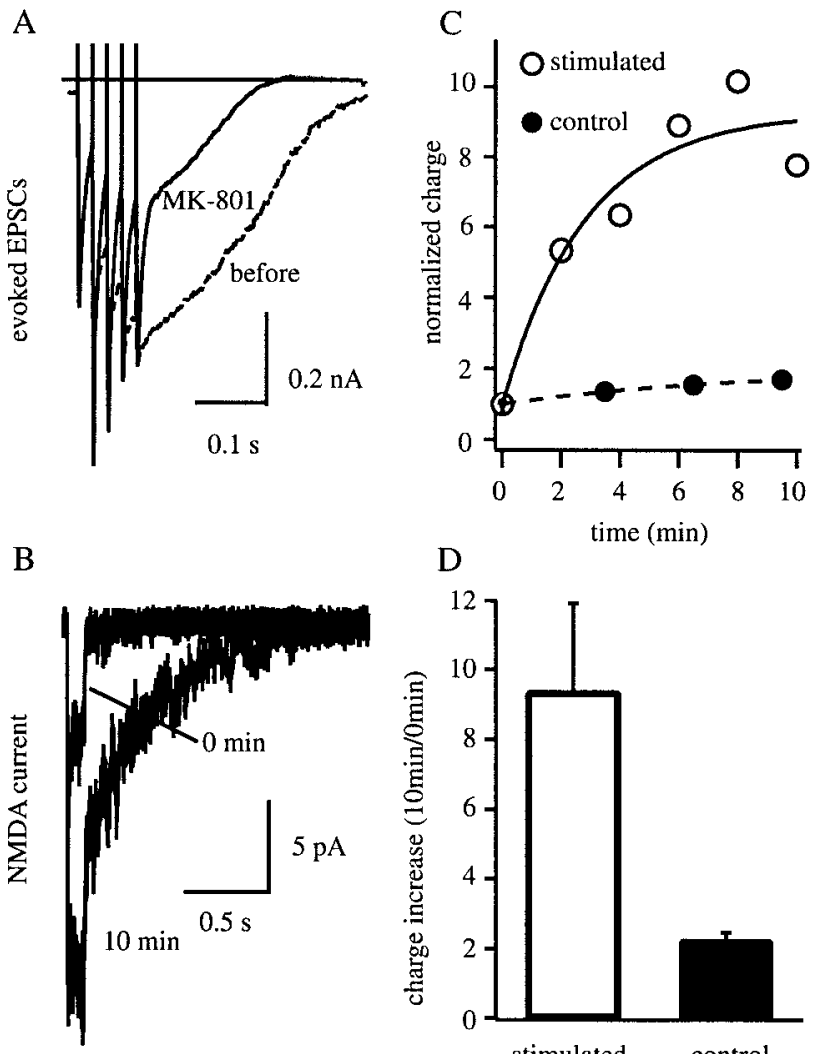

$\mathrm{D}$

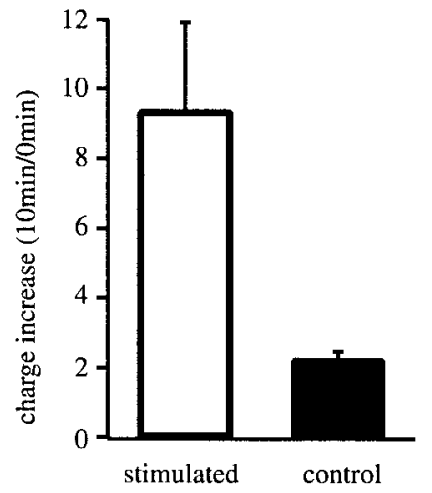

Figure 8. MK-801 block and recovery of synaptically active NMDA receptors. $A$, Dendritic recording in whole-cell mode, during electrically evoked EPSCs (see Materials and Methods). EPSC before (dashed line) and after (solid line) $10 \mathrm{~min}$ bath application of $20 \mu \mathrm{M}$ MK-801, during which synaptic stimulation was given every $20 \mathrm{sec}$. The transient component of the EPSCs (primarily carried by AMPA receptors) did not change, whereas the slow component (primarily carried by NMDA receptors) decreased significantly. Currents were recorded in the presence of $10 \mu \mathrm{M}$ bicuculline, $1 \mathrm{~mm} \mathrm{Mg}^{2+}$, and $0 \mathrm{~mm}$ added glycine. $B$, NMDAmediated current evoked by $10 \mathrm{msec}$ pulse of $1 \mathrm{~mm}$ glutamate to outsideout patches excised near the stimulating electrode (see Materials and Methods). Currents were recorded in the presence of $10 \mu \mathrm{M}$ glycine and in the absence of $\mathrm{Mg}^{2+}$. First trace shows a small NMDA current $(0 \mathrm{~min})$ because of little relief from MK-801 block. Ten minutes later (10 min), a much bigger current was detected as recovery had proceeded. To speed the recovery from block, patches were depolarized every second minute from -80 to $+20 \mathrm{mV}$, and three to four glutamate pulses were applied for $500 \mathrm{msec}$ (see Results). Each trace is an individual sweep ( $V_{\mathrm{h}}$ was -80 $\mathrm{mV}) . C$, NMDA receptor-mediated glutamate current evoked by $10 \mathrm{msec}$ pulses of $1 \mathrm{~mm}$ glutamate current was integrated and normalized to the 0 min value and plotted against time. The charge increased rapidly with time during the relief of MK- 801 block in the case of previous stimulation (open circles with solid line), whereas the control shows only a slight increase ( filled circles with dashed line). D, NMDA charge recorded after 10 min divided by the charge of the first NMDA current $(10 \mathrm{~min} / 0 \mathrm{~min})$ under control or test conditions. NMDA charge increased approximately ninefold in the stimulated cases (open bar; $n=5$ ), whereas in control only twofold increase was observed ( filled bar; $n=6$ ). This suggests that the majority of the glutamate receptors in outside-out patches are synaptic.

the extrasynaptic and the synaptic receptor pools during the time course of our experiments could cause an overestimation of the number of synaptic receptors in our patches $(\mathrm{K}$. R. Tovar and G. L. Westbrook, unpublished observations). Although such complications limit our ability to be quantitative, the data suggest that the majority of glutamate receptors in our patches were located at synaptic sites. 


\section{DISCUSSION}

\section{Summary}

We characterized the amplitude, agonist affinity, kinetics, and single-channel properties of glutamate receptor-mediated currents and compared these properties across a wide range of the apical dendrites of CA1 pyramidal neurons. The main finding is that the mean amplitude of the AMPA current at least doubles with distance from the soma. This distance-dependent increase in AMPA receptor current could be the result of an increased receptor number, receptor density, or some modification of receptor properties. Modified subunit composition (Keinänen et al., 1990; Verdoorn et al., 1991; Mosbacher et al., 1994; Swanson et al., 1997; Dingledine et al., 1999) (for review, see Roche et al., 1994; Soderling et al., 1994; Smart, 1997) or different phosphorylation states (Knapp et al., 1990; Greengard et al., 1991; Hayashi et al., 1997; Mammen et al., 1997; Benke et al., 1998; Banke et al., 2000) can change the kinetic properties, ionic permeability, agonist affinity, current-voltage relationship, single-channel conductance, and maximum open probability of AMPA channels. We examined all of these receptor properties and compared them with distance from the soma and found no significant differences in any of them, whereas on the other hand, channel number increased approximately twofold. These data then strongly suggest that the distance-dependent increase in AMPA current is attributable to a progressive increase in the number of AMPAR in the patches and not to alterations in the basic properties of the receptor-channels.

Most of our results, AMPA receptor agonist affinity, rise time, single-channel conductance, and the concentration dependence of AMPA and NMDA current kinetics, fit well with those published previously for similar experiments (Jonas and Sakmann, 1992; Spruston et al., 1995). There are, however, slight differences in deactivation and desensitization time constants for both receptor types (AMPA and NMDA). The kinetics reported here are slightly faster than those reported previously, and this difference is likely to be attributable to developmental changes occurring in the receptors (our data being from adults and theirs from juveniles) (Jonas and Sakmann, 1992; Spruston et al., 1995). The calculated $P_{0, \max }$ reported here is greater than that reported previously (Spruston et al., 1995), and this is surely the result of our use of a higher glutamate concentration (10 $\mathrm{mm}$ vs $1 \mathrm{~mm})$ for the nonstationary fluctuation analysis experiments (Silver et al., 1996). Finally, this is the first report of a distance-dependent increase in AMPA current amplitude, and this too may be attributable to age differences or to the limited distance of the previous dendritic recordings $(<175 \mu \mathrm{m})$ (Spruston et al., 1995).

\section{Implications for distance-dependent synaptic scaling}

These data fit well with the previous finding that the average conductance of Schaffer collateral synapses increases approximately twofold with distance from the soma and, as expanded on below, suggest that an increase in AMPA receptor numbers may be a primary mechanism of this increased conductance. The postsynaptic densities (PSDs) of Schaffer collateral synapses show a wide range of sizes, and the number of AMPA receptors present at these synapses increases directly with the PSD length (Takumi et al., 1999). Furthermore, spine head volume, PSD area, and presynaptic terminal volume and active zone (AZ) areas all vary together and show a wide range of sizes (Nusser et al., 1998; Schikorski and Stevens, 1999).

In light of these data, it seems possible that the average size of the Schaffer collateral synapses could increase with distance from the soma. In fact, similar changes have already been observed in other central neurons. The size and complexity of various presynaptic and postsynaptic components, including glycine receptor clusters, increases with distance from the soma of Mauthner cells (Triller et al., 1990; Sur et al., 1995). Furthermore, the size of gephyrin clusters, a protein involved in the clustering of glycine receptors, increases in size and complexity with distance from the soma of motoneuron and Ia inhibitory interneurons (Alvarez et al., 1997). Thus, the distal regions of CA1 pyramidal neuron dendrites may possess a greater number of large area Schaffer collateral synapses that contain more AMPA receptors, and we were able to observe this increase as larger-amplitude AMPA currents.

AMPA and NMDA receptors are colocalized in at least $75 \%$ of Schaffer collateral synapses (Takumi et al., 1999), and the ratio of receptor numbers changes as a linear function of PSD diameter. Although the number of AMPA receptors showed a linear correlation to PSD area, the NMDA receptor numbers were independent of synapse size. Our patch data are consistent with these data in that the NMDA receptor number remains constant regardless of distance from soma. That NMDA receptor number remains constant whereas AMPAR numbers increase suggests that the observed increase in AMPA receptor current is not attributable to any distance-dependent changes in patch area, spine density, or receptor access.

That we observed distance-dependent changes in some of the postsynaptic properties of Schaffer collateral synapses does not exclude the possibility of other synaptic changes as well. In fact, because the size of the axon terminal, AZ, and number of docked vesicles all change together with postsynaptic properties, it is likely that presynaptic modifications exist wherever there are postsynaptic changes. Furthermore, as with other synapses, Schaffer collateral terminals are capable of releasing multiple quanta from multiple release sites (Sorra and Harris, 1993; Bolshakov et al., 1997; Larkman et al., 1997; Bykhovskaia et al., 1999; Prange and Murphy, 1999). Theoretically, the occurrence of multisynaptic boutons or the number of release site per bouton could also increase with distance from soma (Sur et al., 1995; Larkman et al., 1997). Any of these changes can cause an elevated synaptic conductance, and, given the covariance of many of these synaptic properties, it seems likely that many changes together will be responsible for the increased conductance of distant synapses.

The above discussions rely on the accuracy of previous reports stating that spine density (spines per square micrometer) is uniform throughout the areas of radiatum innervated by the Schaffer collaterals in rodent hippocampal slices (Andersen et al., 1980; Bannister and Larkman, 1995; Trommald et al., 1995). If, on the other hand, spine density does increase with distance (Megías et al., 2001), then obviously this elevated synapse density could contribute to our observed increase in AMPA current with distance. The role that any such increase in synapse density would play in distance-dependent synaptic scaling is unknown.

\section{Mechanism of distance-dependent scaling}

For synapses to use a distance-dependent scaling to remove the location dependence of synaptic efficacy requires these synapses to have some indication of their physical location in the dendritic arborization. This leads to the following important questions: what signals are available to provide synapses with a distancedependent cue, and how might this signal be translated into changes in synaptic strength? To us, it seems most likely that the distance-dependent regulation of AMPA receptor numbers and 
synaptic conductance are under the control of mechanisms similar to those described for homeostatic plasticity (Turrigiano et al., 1998; Turrigiano and Nelson, 2000). In homeostatic plasticity, synaptic currents are scaled relative to postsynaptic activity, with action potential blockade leading to increases in EPSC amplitude, postsynaptic glutamate responsiveness, AMPAR half-life, and AMPAR numbers. Along these lines, it is now well appreciated that the amplitudes of dendritic action potentials and the calcium influxes associated with them are dependent on distance from the soma, with both decreasing in amplitude with distance (Magee et al., 1998). Furthermore, there is some evidence that resting cytosolic $[\mathrm{Ca}$ ] is reduced with distance from the soma (Magee et al., 1996). Together, these observations lead us to propose that the reduced excitability of the distal dendrites alter the structure and composition of the synapses located there in a manner that increases their unitary conductance.

In conclusion, we observed a distance-dependent increase in the amplitude of AMPA receptor-mediated currents in the apical dendrites of CA1 pyramidal neurons. The magnitude of this increase closely matches that observed for Schaffer collateral synapses across the same range of dendritic regions. In light of this observation and because no differences in a variety of AMPA channel properties were observed, we conclude that an increase in the amount of AMPA receptors elevates the conductance of distant Schaffer collateral synapses in hippocampal CA1 pyramidal neurons.

\section{REFERENCES}

Alvarez FJ, Dewey DE, Harrington DA, Fyffe RE (1997) Cell-type specific organization of glycine receptor clusters in the mammalian spinal cord. J Comp Neurol 379:50-70.

Andersen P, Silfvenius H, Sundberg SH, Sveen O (1980) A comparison of distal and proximal dendritic synapses on CA1 pyramids in guineapig hippocampal slices in vitro. J Physiol (Lond) 307:273-299.

Banke TG, Bowie D, Lee H-K, Huganir RL, Schousboe A, Traynelis SF (2000) Control of GluR1 AMPA receptor function by cAMPdependent protein kinase. J Neurosci 20:89-102.

Bannister NJ, Larkman AU (1995) Dendritic morphology of CA1 pyramidal neurons from the rat hippocampus. II. Spine distribution. J Comp Neurol 360:161-171.

Benke TA, Luthi A, Isaac JT, Collingridge GL (1998) Modulation of AMPA receptor unitary conductance by synaptic activity. Nature 393:793-797.

Bolshakov VY, Golan H, Kandel ER, Siegelbaum SA (1997) Recruitment of new sites of synaptic transmission during the cAMP-dependent late phase of LTP at CA3- CA1 synapses in the hippocampus. Neuron 19:635-646.

Bykhovskaia M, Hackett JT, Worden MK (1999) Asynchrony of quantal events in evoked multiquantal responses indicates presynaptic quantal interaction J Neurophysiol 81:2234-2242.

Clements JD, Lester RAJ, Tong G, Jahr CE, Westbrook GL (1992) The time course of glutamate in the synaptic cleft. Science 258:1498-1501.

Colbert CM, Johnston D (1996) Axonal action-potential initiation and $\mathrm{Na}^{+}$channel densities in the soma and axon initial segment of subicular pyramidal neurons. J Neurosci 16:6676-6686.

Colquhoun D, Jonas P, Sakmann B (1992) Action of brief pulses of glutamate on AMPA/kainate receptors in patches from different neurons of rat hippocampal slices. J Physiol (Lond) 458:261-287.

Dingledine R, Borges K, Bowie D, Traynelis SF (1999) The glutamate receptor ion channels. Pharmacol Rev 51:7-61.

Frick A, Zeigelgansberger W, Dodt HU (2001) Glutamate receptors form Hot Spots on apical dendrites of neocortical pyramidal neurons. J Neurophysiol 86:1412-1421.

Greengard P, Jen J, Nairn AC, Stevens CF (1991) Enhancment of the glutamate response by cAMP-dependent protein kinase in hippocampal neurons. Science 253:1135-1138.

Hayashi Y, Ishida A, Katagiri H, Mishina M, Fujisawa H, Manabe T, Takahashi T (1997) Calcium- and calmodulin-dependent phosphorylation of AMPA type glutamate receptor subunits by endogenous protein kinases in the post-synaptic density. Brain Res Mol Brain Res 46:338-342.

Inasek R, Redman SJ (1973) The amplitude, time course and charge of unitary excitatory post-synaptic potentials evoked in spinal motoneurone dendrites. J Physiol (Lond) 234:665-688.
Jack JJ, Redman SJ (1971) The propagation of transient potentials in some linear cable structures. J Physiol (Lond) 215:283-320.

Jaffe DB, Carnevale NT (1999) Passive normalization of synaptic integration influenced by dendritic architecture. J Neurophysiol 82:3268-3285.

Jonas P, Sakmann B (1992) Glutamate receptor channels in isolated patches from CA1 and CA3 pyramidal cells of the rat hippocampus slice. J Physiol (Lond) 455:143-171.

Keinänen K, Wisden W, Sommer B, Werner P, Herb A, Verdoorn TA, Sakmann B, Seeburg P (1990) A family of AMPA-selective glutamate receptors. Science 249:556-560.

Knapp AG, Schmidt KF, Dowling JE (1990) Dopamine modulates the kinetics of ion channels gated by excitatory amino acids in retinal horizontal cells. Proc Natl Acad Sci USA 87:767-771.

Korn H, Bausela F, Charpier S, Faber DS (1993) Synaptic noise and multiquantal release at dendritic synapses. J Neurophysiol 70:1249-1253.

Larkman AU, Jack JJ, Stratford KJ (1997) Quantal analysis of excitatory synapses in rat hippocampal CA1 in vitro during low-frequency depression. J Physiol (Lond) 505:457-472.

Magee J (1998) Dendritic hyperpolarization-activated currents modify the integrative properties of hippocampal CA1 pyramidal neurons. J Neurosci 18:7613-7624.

Magee JC, Cook EP (2000) Somatic EPSP amplitude is independent of synapse location in hippocampal pyramidal neurons. Nat Neurosci 3:895-903.

Magee JC, Johnston D (1995) Characterization of single voltage-gated $\mathrm{Na}^{+}$and $\mathrm{Ca}^{2+}$ channels in apical dendrites of rat CA1 pyramidal neurons. J Physiol (Lond) 487:67-90.

Magee JC, Avery R, Christie BR, Johnston D (1996) Dihydropyridinesensitive, voltage-gated $\mathrm{Ca}^{2+}$ channels contribute to the resting intracellular $\mathrm{Ca}^{2+}$ concentration of hippocampal CA1 pyramidal neurons. J Neurophysiol 76:3460-3470.

Magee JC, Hoffman D, Colbert C, Johnston D (1998) Electrical and calcium signaling in dendrites of hippocampal pyramidal neurons. Annu Rev Physiol 60:327-346.

Mammen A, Kameyama K, Roche KW, Huganir RL (1997) Phosphorylation of the $\alpha$-amino-3-hydroxy-5-methylisoxazole-4-proprionic acid receptor GluR1 subunit by calcium/calmodulin-dependent kinase II. J Biol Chem 272:32528-32533.

Megías M, Emre ZS, Freund TF, Gulyas AI (2001) Total number and distribution of inhibitory and excitatory synapses on hippocampal CA1 pyramidal cells. Neuroscience 102:527-540.

Mosbacher J, Schoepfer R, Monyer H, Burnashev N, Seeburg PH, Ruppersberg JP (1994) A molecular determinant for submillisecond desensitization in glutamate receptors. Science 266:1059-1062.

Nusser Z, Lujan R, Laube G, Roberts JD, Molnar E, Somogyi P (1998) Cell type and pathway dependence of synaptic AMPA receptor number and variability in the hippocampus. Neuron 21:545-559.

Pettit DL, Augustine GJ (2000) Distribution of functional glutamate and GABA receptors on hippocampal pyramidal cells and interneurons. J Neurophysiol 84:28-38.

Prange O, Murphy TH (1999) Analysis of multiquantal transmitter release from single cultured cortical neuron terminals. J Neurophysiol 81:1810-1818.

Rall W (1962) Theory of physiological properties of dendrites. Ann NY Acad Sci 96:1071-1079.

Roche KW, Tingley WG, Huganir RL (1994) Glutamate receptor phosphorylation and synaptic plasticity. Curr Opin Neurobiol 4:383-388.

Rosenmund C, Feltz A, Westbrook GL (1995) Synaptic NMDA receptor channels have a low open probability. J Neurosci 15:2788-2795.

Schikorski T, Stevens CF (1999) Quantitative fine-structural analysis of olfactory cortical synapses. Proc Natl Acad Sci USA 96:4107-4112.

Sigworth FJ (1980) The variance of sodium current fluctuations at the node of Ranvier. J Physiol (Lond) 307:97-129.

Silver AR, Cull-Candy SG, Takahashi T (1996) Non-NMDA glutamate occupancy and open probability at a rat cerebellar synapse with single and multiple release sites. J Physiol (Lond) 494 1:231-250.

Smart TG (1997) Regulation of excitatory and inhibitory neurotransmitter-gated ion channels by protein phosphorylation. Curr Opin Neurobiol 7:358-367.

Soderling TR, Tan SE, McGlade-McCulloh E, Yamamoto H, Fukunaga K (1994) Excitatory interactions between glutamate receptors and protein kinases. J Neurobiol 25:304-311.

Sorra KE, Harris KM (1993) Occurrence and three dimensional structure of multiple synapses between individual radiatum axons and their target pyramidal cells in hippocampal area CA1. J Neurosci 13:3736-3747.

Spruston N, Jonas P, Sakmann B (1995) Dendritic glutamate receptor channels in rat hippocampal CA3 and CA1 pyramidal neurons. J Physiol (Lond) 482:325-352. 
Stricker C, Field AC, Redman SJ (1996) Statistic analysis of amplitude fluctuations in EPSCs evoked in rat CA1 pyramidal neurones in vitro. J Physiol (Lond) 490:419-441.

Sur C, Triller A, Korn H (1995) Morphology of the release site of inhibitory synapses on the soma and dendrite of an identified neuron. J Comp Neurol 351:247-260.

Swanson GT, Kamboj SK, Cull-Candy SG (1997) Single-channel properties of recombinant AMPA receptors depend on RNA editing, splice variation, and subunit composition. J Neurosci 17:58-69.

Takumi Y, Ramírez-León V, Laake P, Rinvik E, Ottersen OP (1999) Different modes of expression of AMPA and NMDA receptors in hippocampal synapse. Nat Neurosci 2:618-624.

Triller A, Seitandou T, Franksson O, Korn H (1990) Size and shape of glycine receptor cluster in a central neuron exhibit a somato-dendritic gradient. New Biol 2:637-641.

Trommald M, Jensen V, Andersen P (1995) Analysis of dendritic spines in rat CA1 pyramidal cells intracellularly filled with a fluorescent dye. J Comp Neurol 353:260-274.

Turrigiano GG, Nelson S (2000) Hebb and homeostasis in neuronal plasticity. Rev Curr Opin Neurobiol 10:358-364.

Turrigiano GG, Leslie KR, Desai NS, Rutherford LC, Nelson S (1998) Activity-dependent scaling of quantal amplitude in neocortical neurons. Nature 391:892-896.

Verdoorn TA, Burnashev N, Monyer H, Seeburg PH, Sakmann B (1991) Structural determinants of ion flow through recombinant glutamate receptor channels. Science 252:1715-1718. 